\title{
Clinical outcome of short daily hemodialysis in the elderly
}

\author{
Patricia Villié $^{1} \cdot$ Maxime Dauvergne ${ }^{2} \cdot$ Catherine Maheas $^{1} \cdot$ Florence Vendé $^{2} \cdot$ Pablo Urena $^{2} \cdot$ Christophe Ridel $^{1}$. \\ Maxime Touzot ${ }^{1}$ (1)
}

Received: 5 July 2021 / Accepted: 18 August 2021 / Published online: 28 August 2021

(c) The Author(s) 2021

Keywords Daily dialysis $\cdot$ Elderly $\cdot$ Survival

Recent results from the frequent hemodialysis network (FHN) daily trial confirmed the clinical and biological benefits of in-center short daily hemodialysis (SDHD) compared to conventional thrice-weekly hemodialysis (HD) [1]. SDHD improves cardiovascular outcome, with better fluid volume balance as well as blood pressure and phosphate control, and moreover, it results in significantly longer survival after 2 years of treatment. However, this trial focused on fairly young patients, mainly aged under 50 . Clinicians may consider it useful to treat elderly patients with a softer technique such as SDHD because of their numerous comorbidities.

In the present study, we report a retrospective assessment of $37 \mathrm{HD}$ patients who were switched from conventional thrice-weekly HD to in-center SDHD. They were divided into two groups according to the median age of 65 years: SDHD $<65(\mathrm{~N}=19)$ and SDHD $\geq 65(\mathrm{~N}=18)$. SDHD was initiated at the patient's request in $58 \%$ of the SDHD $<65$ cohort, and by medical decision in $78 \%$ of the SDHD $\geq 65$ group. Demographic characteristics at baseline are shown in Table S1. SDHD $\geq 65$ had more cardiovascular diseases.

Interdialytic weight gain (IDWG) was significantly reduced by SDHD in all patients (Fig. S1), but to a greater extent in the SDHD $\geq 65$ group $(0.9 \pm 0.6$ vs $1.9 \pm 0.9 \mathrm{~kg}$, $\mathrm{p}<0.01$ ). After 12 months of follow-up, total weekly IDWG decreased slightly in SDHD $\geq 65$ to $5.1 \pm 3.6$ vs $7.2 \pm 5.5 \mathrm{~kg}$ but remained stable in SDHD $<65(8 \pm 5.1 \mathrm{vs} 7.6 \pm 4.9 \mathrm{~kg})$, without statistical significance. Data regarding urine volume were not available. The dry weight remained stable in both groups during the follow-up.

Maxime Touzot

maxime.touzot@auraparis.org

1 Service de Dialyse et Aphérèse Thérapeutique, AURA, 75014 Paris, France

2 Centre de Dialyse AURA Saint-Ouen, Saint-Ouen, France
Pre-dialysis systolic blood pressure (pre-HD sBP) was higher for SDHD $<65$ compared to SDHD $\geq 65$ during the follow-up: $141 \pm 20$ vs $127 \pm 23 \mathrm{mmHg}(p=0.005)$, and $136 \pm 21$ vs $121 \pm 28 \mathrm{mmHg}(p=0.015)$ (Fig. S2A). A similar trend was observed for pre-dialysis diastolic BP (Fig. S2B).

After 12 months of follow-up, the prescription of antihypertensive drugs was similar in both groups: the mean number of tablets per day was $1.6 \pm 1.3$ vs $1.9 \pm 1.3(p=0.13)$ in SDHD $<65$ patients and $1.4 \pm 1.3$ vs $1.5 \pm 0.8(\mathrm{p}=0.98)$ in SDHD $\geq 65$ patients. No difference in erythropoietin stimulating agent (ESA) dose was observed ("Supplementary files").

At baseline, SDHD $<65$ had higher mean albumin $(3.7 \pm 0.6$ vs $3.4 \pm 0.4 \mathrm{~g} / \mathrm{dL}, \mathrm{p}=0.04)$ and lower mean prealbumin levels $(0.25 \pm 0.1$ vs $0.38 \pm 0.1, p \leq 0.001)$ compared to SDHD $\geq 65$ (Fig S3A). Albumin levels in more than half of the SDHD $\geq 65$ were below $3.5 \mathrm{~g} / \mathrm{dL}$. After 12 months of follow-up, albumin increased up to $3.9 \pm 0.5 \mathrm{~g} / \mathrm{dL}$ in SDHD $<65$ but did not reach statistical significance. The mean prealbumin level remained stable. No benefit of SDHD on nutritional parameters was observed in the SDHD $\geq 65$ group, as albumin and pre-albumin levels remained stable during the first year, but at lower levels compared to SDHD $<65$.

Mean serum phosphate levels decreased in all patients during follow-up, but mainly in SDHD $\geq 65$ : $1.20 \pm 0.3 \mathrm{mmol} / \mathrm{L}$ vs $1.48 \pm 0.5 \mathrm{mmol} / \mathrm{l}$ in $\mathrm{SDHD}<65$, $\mathrm{p}=0.09$ (Fig. S3C).

The mean number of vascular events per patient per year (angiography-requiring procedure) was similar between the SDHD $<65$ and SDHD $\geq 65$ group $(0.9 \pm 1.8$ vs $0.70 \pm 1$, $p=0.89$ ).

The SDHD $\geq 65$ patient group was matched to a control group, which included 49 prevalent HD patients $\geq 65$ years old, with at least 24 months of dialysis. Demographic characteristics are shown in S2. Eight patients from the SDHD 
$\geq 65$ group died, most of them of cardiovascular events $(n=6)$. The 24-month survival rate of SDHD $\geq 65$ patients was not statistically different compared to the controls (67 vs $74 \%, \mathrm{p}=0.12$ ) (Fig. 1).

Two distinctive features of our elderly patients should be noted. Firstly, they had an altered baseline nutritional status including persistently low albumin and pre-albumin levels. Whilst SDHD controlled hyperphosphatemia in younger patients, in the elderly it appeared to promote hypophosphatemia, which has been shown to be an independent risk factor of mortality [2]. In our population, hypophosphatemia may be more indicative of the malnutrition status than of the efficacy of SDHD on phosphate removal. Secondly, more than half of our elderly group had a systolic BP below $120 \mathrm{mmHg}$ which is also an independent risk factor of mortality [3]. This low BP could be due to diffuse arteriosclerosis and altered cardiac function. The comparable survival rate between the SDHD $\geq 65$ and the control group should be interpreted cautiously. Indeed, we cannot exclude that the survival rate of SDHD $\geq 65$ patients might have been worse if they had not been switched to SDHD.

Our study has several limitations. It is single-center, retrospective and involves a small number of patients. The comparison using a historical control group may have introduced bias, as both populations cannot be matched according to their dialysis vintage. Data regarding Quality of Life were not available. However, to our knowledge, this is the first study to focus on the outcome of elderly patients undergoing in-center SDHD.

Overall, our study demonstrated that SDHD for patients $\geq 65$ years old is feasible, provides a clinical benefit

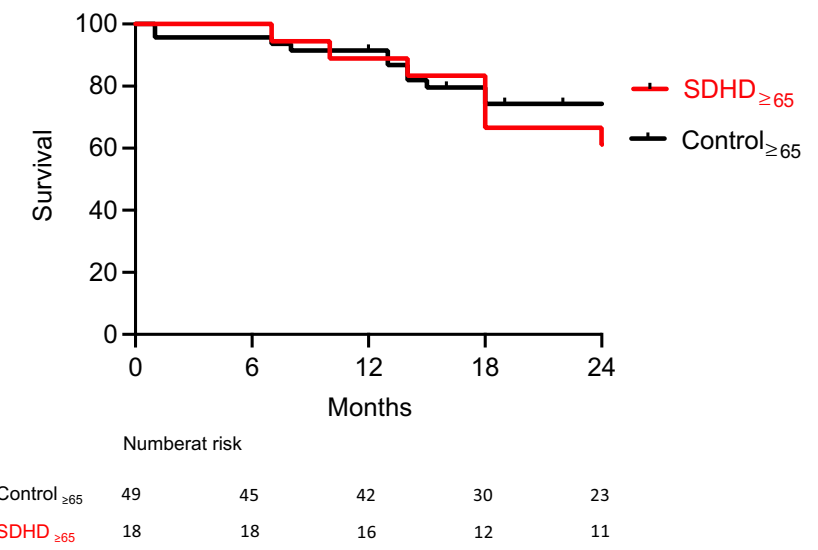

Fig. 1 Two-year survival curves of elderly patients treated by incenter short daily hemodialysis. The graph depicts the survival curves up to 24 months after commencing short daily hemodialysis (SDHD) for patients older than 65 years (SDHD $\geq 65$ ) in red, and the control group in black. The difference in survival between SDHD $\geq 65$ and control $>65$ did not reach statistical significance $(p=0.13$, log-rank test) (colour figure online) regarding IDWG and should be considered an option for this fragile population.

Supplementary Information The online version contains supplementary material available at https://doi.org/10.1007/s40620-021-01148-1.

Acknowledgements The authors would like to thank Dr Clerté, Dr Morel, Dr Roux, Dr Katerinis, and Dr Hude and all the nurses working in the Philippe Laporte Unit.

\section{Declaration}

Conflict of interest The authors declare no competing financial support or interests.

Ethical statement The study sponsor was the Groupe Hospitalier Paris Saint-Joseph, and was approved by the institutional ethics committee (institutional review board number IRB00012157) and registered on the French health data hub. All patients were given information by their physician. The patients' non-opposition to the use of their data for research was also collected in accordance with European regulations (General Data Protection Regulation).

Open Access This article is licensed under a Creative Commons Attribution 4.0 International License, which permits use, sharing, adaptation, distribution and reproduction in any medium or format, as long as you give appropriate credit to the original author(s) and the source, provide a link to the Creative Commons licence, and indicate if changes were made. The images or other third party material in this article are included in the article's Creative Commons licence, unless indicated otherwise in a credit line to the material. If material is not included in the article's Creative Commons licence and your intended use is not permitted by statutory regulation or exceeds the permitted use, you will need to obtain permission directly from the copyright holder. To view a copy of this licence, visit http://creativecommons.org/licenses/by/4.0/.

\section{References}

1. Chertow GM, Levin NW, Beck GJ et al (2016) Long-term effects of frequent in-center hemodialysis. J Am Soc Nephrol 27:1830 1836. https://doi.org/10.1681/ASN.2015040426

2. Lertdumrongluk P, Rhee CM, Park J et al (2013) Association of serum phosphorus concentration with mortality in elderly and nonelderly hemodialysis patients. J Ren Nutr 23:411-421. https:// doi.org/10.1053/j.jrn.2013.01.018

3. Turner JM, Peixoto AJ (2017) Blood pressure targets for hemodialysis patients. Kidney Int 92:816-823. https://doi.org/10.1016/j. kint.2017.01.038

Publisher's Note Springer Nature remains neutral with regard to jurisdictional claims in published maps and institutional affiliations. 